\title{
On the Plasma Deposition of Vancomycin-Containing Nano-capsules for Drug- Delivery Applications
}

\author{
Chiara Lo Porto $^{\mathrm{a}}$, Fabio Palumbo ${ }^{\mathrm{b} *}$, Judit Buxadera-Palomero $^{\mathrm{c}}$, Cristina Canal $^{\mathrm{c}}$, Petr Jelinek ${ }^{\text {d.e }}$, \\ Lenka Zajickova $^{\text {d,e }}$, Pietro Favia ${ }^{\text {b,** }}$
}

a. Department of Chemistry, University of Bari “Aldo Moro”, Via Orabona 4, 70126 Bari, Italy

b. Institute of Nanotechnology, National Research Council of Italy, c/o Department of Chemistry, University of Bari

"Aldo Moro", Via Orabona 4, 70126 Bari, Italy

c Biomaterials, Biomechanics and Tissue Engineering Group, Department of Materials Science and Metallurgical Engineering, Technical University of Catalonia, EEBE, Eduard Maristany 10-14, 08019 Barcelona, Spain

d. RG Plasma Technologies, CEITEC - Central European Institute of Technology, Masaryk University, Purkyňova 123, 61200 Brno, Czech Republic

e. Department of Physical $\backslash$ Electronics, Faculty of Science, Masaryk University, Kotlářská 2, 61137 Brno, Czech Republic

f. Department of Biosciences, Biotechnologies and Biopharmaceutics, University of Bari “Aldo Moro”, Via Orabona 4, 70126 Bari, Italy

* Corresponding authors:

Pietro Favia: pietro.favia@uniba.it

Fabio Palumbo: fabio.palumbo@uniba.it

\begin{abstract}
Aerosol-assisted atmospheric pressure plasma allows for a one-step synthesis of vancomycin-containing nano-capsules. Morphological and chemical analyses were carried out to estimate how different discharge parameters affect the plasma deposition process. Nano-capsules size and abundance largely depend on the shell precursor content in the gas feed and on the drug concentration in the aerosol solution. Based on these results a deposition mechanism is proposed, where, interestingly, the key step is the formation of the nano-capsules in the plasma phase. Furthermore, the related antibacterial activity is proved against Staphylococcus aureus. Preliminary release tests indicate the possible exploitation of the plasma-deposited vancomycin-containing nanocapsules in the drug delivery field, and systems based on other bioactive molecules can be expected.
\end{abstract}




\section{Introduction}

Nano-capsules are nanometric vescicular systems with a core-shell structure consisting of a cavity and a surrounding polymeric membrane or coating. An active compound can be contained inside the cavity, in liquid or solid form, or even as a molecular dispersion; the active substance can also be carried at the surface of the nano-capsules or imbibed in their polymeric membrane.

The most widely investigated application of nano-capsules is probably as drug delivery systems. ${ }^{1-3}$ Numerous qualities make these systems extremely suitable and vastly used for drug delivery: the subcellular size of nano-capsules, for example, allows more efficient uptake of the compounds in cells. Other interesting qualities are: improved stability of the active substance in the capsule, biocompatibility and biodegradability, high drug-encapsulation efficiency, and shell protection of the drug against degradation factors. These systems generally aim at delivering a specific drug where required, rather than in the entire body, in low amount rather than in massive quantities, avoiding a high risk of developing resistance. The ideal amount of antibacterial compounds released should be higher than the Minimum Inhibiting Concentration (MIC) of the target organisms, but well below the cytotoxicity threshold. The technological issue concerning nano-capsules synthesis is raising great interest. Classical methods for the preparation of nano-capsules are: nano-precipitation, emulsiondiffusion, double emulsification, emulsion-coacervation, polymer-coating and layer-by-layer technique. $^{4}$

Nano-capsules containing a bioactive molecule can be considered a biocomposite material with a very peculiar morphology. Biocomposite coatings, in general, consist of two fundamental components: a bioactive molecule, and a matrix in which the molecule is embedded. The nature of the molecule and that of the matrix can be properly selected in order to obtain different coatings for a very wide range of applications, including food packaging, ${ }^{5,6}$ biosensors, ${ }^{7-15}$ and bioreactors. ${ }^{16-18}$ In the biomaterials field, particularly for tissue engineering and regenerative medicine applications, biocomposite coatings are being tested as drug delivery systems, with the aim of providing anti- 
bacterial or enhanced cell-growth properties either on $3 \mathrm{D}$ scaffolds ${ }^{19,20}$ or on flat substrates. ${ }^{21-26} \mathrm{~A}$ huge variety of processes have been studied to achieve the synthesis of biocomposite coatings; the most relevant are: photo-polymerization, ${ }^{27}$ initiated-Chemical Vapor Deposition (i-CVD), ${ }^{22}$ 3D printing, ${ }^{19}$ micro-dispensing ${ }^{21}$ and wet chemistry. ${ }^{13,20,28,29}$

All the above-mentioned techniques for nano-capsules and biocomposite coatings synthesis present in general some drawbacks, especially for the scale-up of the process; for example, multi-step protocols are often proposed, that include the use of potentially harmful solvents and reagents. Plasma processes may provide a solution to reduce these drawbacks; moreover, they allow fine tuning of coating properties without altering the bulk properties of the target material, with limited use of chemicals and solvents. ${ }^{30,31}$

A one-step process has been optimized by Palumbo et al. ${ }^{32}$ for the plasma deposition of nanometric hydrophilic biocomposite coatings embedding active Lysozyme, an antimicrobial enzyme. The deposition method is developed in an Atmospheric Pressure Plasma (APP) reactor configured as Dielectric Barrier Discharge (DBD), coupled with an atomizer to feed the gas discharge low vapor pressure pure liquids, salts solutions and suspensions of nano-particles. ${ }^{32-40,47}$ This configuration allows the deposition on any kind of flat substrate.

To deposit the biocomposite coatings the aerosol solution atomized into the reactor must contain the bioactive molecule dissolved in a suitable solvent. The matrix precursor is also inlet into the reactor, as gas or vapor, along with a buffer gas (e.g., He, Ar) to generate the aerosol and to sustain the discharge. When the feed passes through the discharge, the precursor and the vapour of the solvent are fragmented in radicals and atoms that originate the matrix of the coating; at the same time, nanometric drops of the aerosol are present in the plasma environment and participate to the deposition process. The bioactive molecule in the droplets is protected against the plasma environment, and is found unaltered embedded in the final coating, with retained structure and 
activity. ${ }^{33-35}$ Thanks to the mild discharge conditions, aerosol-assisted APP processes enable the use of thermo-degradable molecules providing easy-to-handle technical equipment.

Vancomycin is a glycopeptide antibiotic produced by Streptococcus Orientalis, well known for drug delivery applications, with a broad-spectrum activity, including against methicillin-resistant strains of Staphylococcus aureus. Vancomycin has often been encapsulated in spherical micro/nanoparticles made of polymeric materials such as poly( $\varepsilon$-caprolactone), for bone implants, ${ }^{41}$ spray dried chitosan, ${ }^{42}$ or N-trimethyl chitosan, prepared by single ionic complexation. ${ }^{43}$ Vancomycin-containing coatings produced by electrodeposition ${ }^{44-46}$ and adsorption methods ${ }^{46}$ are also reported.

We have recently published a communication on the direct synthesis of vancomycin-containing nanocapsules using an aerosol-assisted APP process. ${ }^{47}$ It represents an absolute novelty since, for the first time, a one-step, easy-to-handle, eco-friendly, plasma process is shown for the synthesis of nanocapsules embedding a bioactive molecule. As for previous works ${ }^{32,47}$ ethylene was selected as precursor of the shell of the capsules; vancomycin was selected to be embedded in the capsules from an aqueous aerosol, helium was used as buffer and aerosol-forming. Surprisingly, in specific experimental conditions, layers of nano-capsules resulted on the zone close to the gas inlet of the ground electrode of the DBD, instead of a flat coating embedding the biomolecule. ${ }^{32}$

The experiments in this paper highlight more in detail how the variation of some discharge parameters can affect the morphology and the deposition mechanism of vancomycin-embedding nano-capsules. Furthermore, the optimized materials have been tested for their drug-release properties in water, as well as for their antibacterial activity.

\section{Experimental Section}

\subsection{Materials}

He $99.999 \%$ and ethylene $99.95 \%$ (Air Liquide) were used as feed gases in the APP deposition process. $0-15 \mathrm{mg} / \mathrm{mL}$ (corresponding to a maximum concentration of $10^{-2} \mathrm{~mol} / \mathrm{l}$ ) solutions of 
vancomycin hydrochloride (MW $1449.2 \mathrm{~g} / \mathrm{mol}$; powder, Molecular Biology Grade, from ABCR), in water of Milli-Q quality (Millipore, Bedford, MA) were used to generate the aerosol. Water, acetonitrile (ACN), formic acid of HPLC grade were used without further purification for HPLC analysis. For the release tests and for the determination of the antibacterial activity of the coatings Milli-Q quality water was employed. All chemicals used were of analytical grade unless otherwise stated.

Shards $\left(1 \times 1 \mathrm{~cm}^{2}\right)$ of $710 \mu \mathrm{m}$ thick double-face polished crystalline silicon (100) wafers (MicroChemicals $\mathrm{GmbH}$ ) were used as substrates for the deposition experiments. For the release tests, the coatings have been deposited onto $0.25 \mathrm{~mm}$ thick Polycarbonate (PC, Goodfellow, $1 \mathrm{x} 1 \mathrm{~cm}^{2}$ ). The analysis of the antibacterial activity has been carried out on films deposited onto titanium disks (grade 2, $10 \mathrm{~mm}$ dia, VDM metals, Germany) polished with colloidal silica suspension (0.05 $\mu \mathrm{m}$ size, Buehler, USA).

\subsection{DBD Reactor}

The homemade DBD reactor is the same as the one schematically shown in ref $[32,47]$. It consists of two parallel plates silver electrodes, $5 \times 8 \mathrm{~cm}^{2}$ wide, $5 \mathrm{~mm}$ apart, both covered with $0.63 \mathrm{~mm}$ thick alumina sheets. The electrode set up is confined in a sealed Plexiglas chamber. The aerosol of 0-15 $\mathrm{mg} / \mathrm{mL}$ vancomycin aqueous solution was generated with an atomizer (mod. 3067, TSI) working with He at a flow rate of $5 \mathrm{slm}$. Previous works indicated that in this condition a mass flow rate of $136 \pm 7$

$\mu \mathrm{g} / \mathrm{min}$ of aerosol was obtained. As stated by different authors ${ }^{33,34}$ the diameter range of the droplets produced by the atomizer, used in the present work, in similar conditions is typically sub-micrometric. Ethylene was fed in the chamber at a flow rate of 5-200 sccm, and an auxiliary line allowed He to be directly inlet in the chamber when needed. Gas flow rates were controlled by means of electronic mass flow controllers (MSK instruments). The gas/aerosol feed was let from the shorter side of the reactor, through the plasma zone between the electrodes, and was pumped out by an aspirator located 
on the opposite side. The Continuous Wave (CW) discharge was ignited between the electrodes using a corona power supply (PVM500, Information Unlimited). The electrical properties of the plasma were investigated for determining the voltage and the current delivered to the system with a highvoltage (P6015A, Tektronix) probe and a resistance type current probe, both connected to an oscilloscope (TDS 20145C, Tektronix). The average power was obtained by multiplying the energy per voltage cycle by the frequency of the applied field; the energy per cycle was calculated from the time integral of the current times the voltage in one cycle. The applied peak-to peak voltage was always kept at $4 \mathrm{kV}$ at a frequency of $24 \mathrm{kHz}$, resulting in a power of $1.3 \mathrm{Wcm}^{-2}$, in the experimental conditions used in this work. Before each deposition experiment, a cleaning step of the electrodes was performed by igniting for 5 min a discharge fed with a water aerosol carried by He with a flow rate of $5 \mathrm{slm}$. Substrates were positioned on the bottom electrode, always within $3 \mathrm{~cm}$ close to the inlet of the feed, and the chamber was purged with a $5 \mathrm{slm}$ He stream for $5 \mathrm{~min}$. To better understand the deposition process mechanism, the discharge duration has been tuned in the range 1-13 min. Discharges ignited in Pulsed Mode (PM) were also investigated, in this case a pulse generator was controlling the power supply with an on-time of $40 \mathrm{~ms}$ and an off time of $80 \mathrm{~ms}$, hence a duty cycle of $33 \%$.

With the purpose of modulating the release rate of vancomycin from the coating and in the antibacterial essays, in some samples an additional layer (100 nm thick) has been deposited on top of the bioactive coating, to act as a diffusion barrier layer. Such top coating has been deposited in a continuous discharge fed with $20 \mathrm{sccm}$ ethylene and $5 \mathrm{slm}$ He for $3 \mathrm{~min}$.

\subsection{Chemical and morphological characterization of the samples}

Fourier Transform Infrared Spectroscopy (FT-IR) was carried out to characterize the bulk of the coatings. FT-IR spectra (32 scans per analysis, $4 \mathrm{~cm}^{-1}$ resolution) were obtained in transmission mode with a Vertex 70V Bruker spectrometer. The spectrometer was evacuated to less than $150 \mathrm{~Pa}$ for 10 
min before each acquisition. Spectra were normalized by the maximum intensity of the O-H/N-H stretching band at $3400 \mathrm{~cm}^{-1}$.

Scanning Electron Microscopy (SEM) was carried out to analyse the morphology of the samples with a Zeiss Supra 40 equipped with a Gemini field-effect emission gun. Analyses were carried out at an extraction voltage of $3 \mathrm{kV}$, onto samples sputter coated with a $20 \mathrm{~nm}$ thick layer of chromium. For each acquisition the brightness, the contrast and the working distance (varying in the range of 2-4 $\mathrm{mm}$ ) have been optimized.

Static Water Contact Angle (WCA) measures were performed with a Rame'-Hart Inc, 100-00-230 goniometer (5ml drop, double distilled water).

\subsection{Vancomycin release tests}

Plasma processed samples $1 \times 2 \mathrm{~cm}^{2}$ wide were put into 12-well Iwaki polystyrene plates with flat base (Sterilin Limited, Newport, UK), covered with $800 \mu \mathrm{L}$ of water, and incubated at room temperature. The amount of vancomycin released was monitored collecting $300 \mu \mathrm{L}$ of supernatant, at different soaking time, up to 4 days. Every withdrawn aliquot of liquid was refurbished with $300 \mu \mathrm{L}$ of fresh distilled water, to keep the dipping volume constant. The release solution was analysed with a spectrophotometer UV-2401PC (Shimadzu) set at $280 \mathrm{~nm}$. The release solution was also analysed by Mass Spectrometry Liquid Chromatography, to confirm the integrity of the released vancomycin molecule. A C18 column was used ( $2.1 \mathrm{~m}$ length, $250 \mu \mathrm{m}$ dia, $1.7 \mu \mathrm{m}$ packing, $0.2 \mathrm{~mL} / \mathrm{min}$ flow rate) with a $0.1 \%$ formic acid $\mathrm{H}_{2} \mathrm{O} / \mathrm{ACN} 95 / 5$ solution as mobile phase.

\subsection{Antibacterial activity of the coatings}

Two different tests have been performed. For the Agar diffusion test a bacteria suspension (Staphylococcus aureus, CCUG 15915, Culture Collection of the University of Göteborg, Sweden) incubated overnight was diluted to an absorbance of $0.20 \pm 0.01$ at $600 \mathrm{~nm}$, giving approximately $1 \cdot 10^{8}$ 
$\mathrm{CFU} / \mathrm{mL}$. An aliquot of $100 \mu \mathrm{L}$ of the suspension was seeded on the agar plate and the plasma coated Ti samples were placed upside down in the plate. The plates were then incubated overnight at $37^{\circ} \mathrm{C}$ and the zone where the growth of bacteria is inhibited was measured around the samples.

The growth inhibition (double-well) test, instead, was performed in order to evaluate the dynamic antibacterial activity of eluents from the samples. A 48 wells plate (Nunc) with adjacent pair wells connected was used: one for the titanium sample and the other one for the measurement of the bacteria growth curve by UV-vis spectrophotometer, as previously reported. ${ }^{49}$ Bacteria for this assay were grown overnight and diluted to an optical density of 0.02 , corresponding to $10^{6} \mathrm{CFU} / \mathrm{mL}$. A $1 \mathrm{~mL}$ aliquot of suspension was placed in each well and the absorbance at $600 \mathrm{~nm}$ was monitored with a multiplate reader (Multimode microplate reader, Synergy ${ }^{\mathrm{TM}}$ HTX) every $10 \mathrm{~min}$. Before each measurement, the plate was shaken for $3 \mathrm{~s}$ to ensure the homogeneity of the suspension.

\section{Results and discussion}

\subsection{Characterization of the coatings}

In our previous work 47, we presented the core-shell organization of the vancomycin-containing nano-capsules constituting the APP deposited coatings obtained from continuous and modulated plasma. The structure of the capsules could be easily detected and it was also observed that, when deposited in continuous mode, the spherical structures appeared bigger than those formed in DBDs ignited in pulsed mode, where taller aggregates of slightly smaller spheres were formed (Figure 1a and $1 \mathrm{~b}$ ). After immersion of the samples in water, the PM coating largely delaminated ${ }^{47}$, whereas the CW one showed just a $17 \%$ decrease in thickness, and moreover in the latter some of the spheres opened revealing a cavity, or collapsed upon themselves, as clearly shown in Figure 1c. Confocal microscopy observations of the coatings synthesized by feeding the discharge with an aerosol of a 
fluorescein solution, instead of vancomycin, demonstrated the presence of the aerosol solute inside the nano-capsules.

Figure 2 shows SEM images of coatings deposited in $\mathrm{CW}$ when the $\mathrm{C}_{2} \mathrm{H}_{4}$ flow rate was changed in the range 5-200 sccm. It can be observed that, the density of nano-capsules at the surface of the coating increases with the ethylene flow rate; furthermore, at a $\mathrm{C}_{2} \mathrm{H}_{4}$ flow rate of $200 \mathrm{sccm}$ their average diameter is drastically lower.

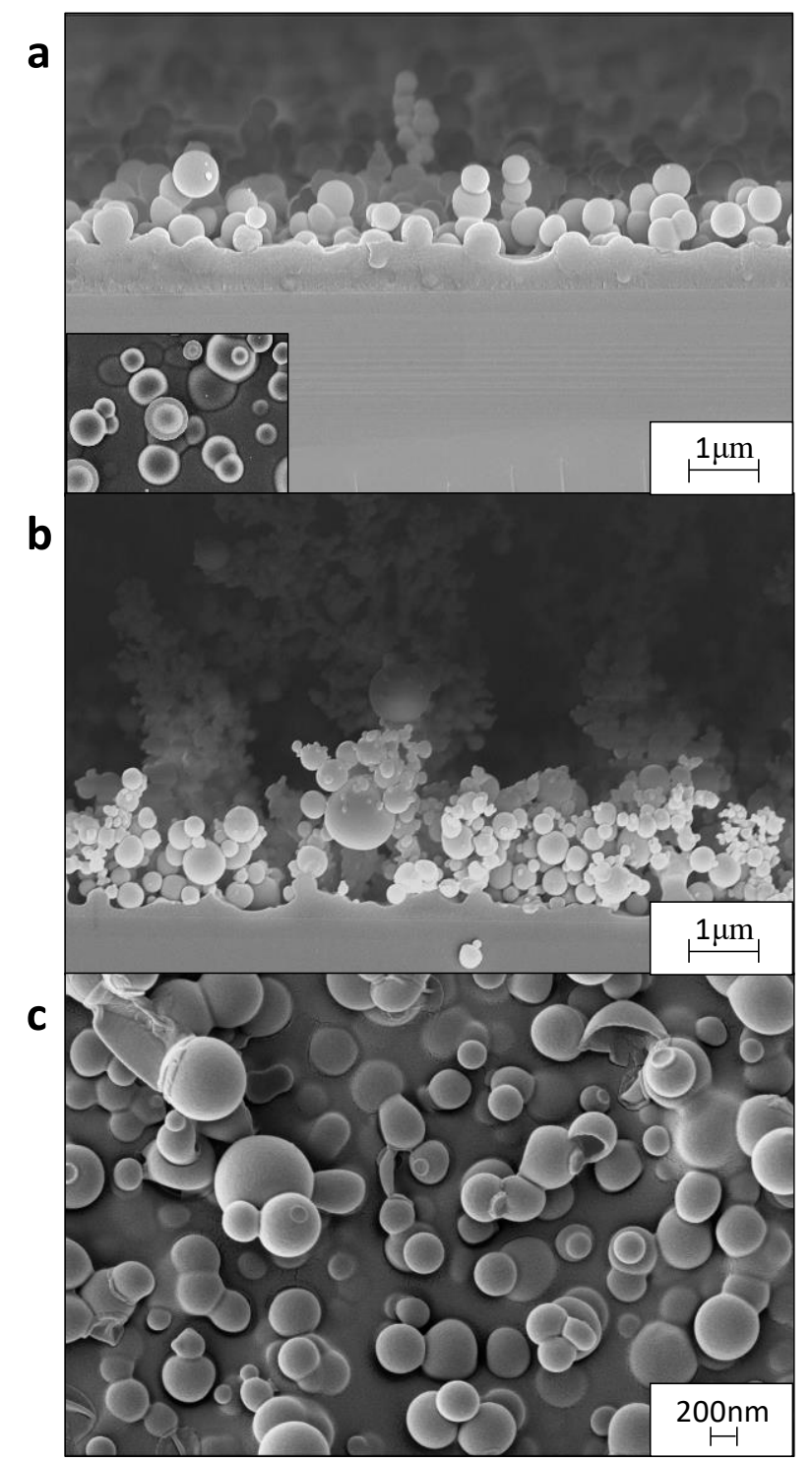

Figure 1 - Cross section SEM image of coatings plasma deposited (20 sccm ethylene, $5 \mathrm{slm}$ He, 15 $\mathrm{mg} / \mathrm{ml}$ of vancomycin solution) in a) CW (inset top view) and b) PM condition. c) Top view SEM image of a CW plasma deposited coating after $60 \mathrm{~min}$ immersion in water. Adapted from ref. 47 by permission of The Royal Society of Chemistry. 


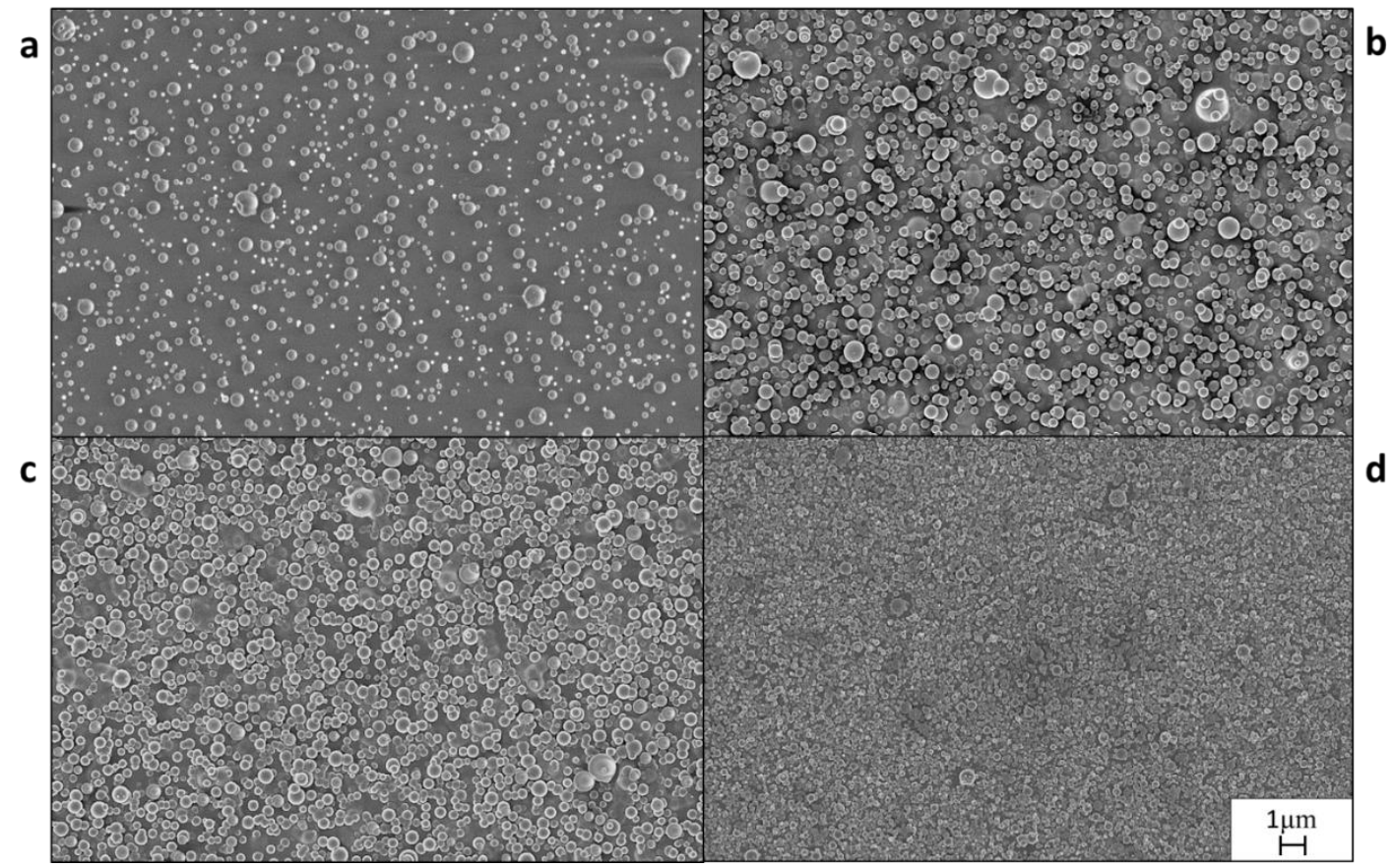

Figure 2 - SEM images of coatings deposited in continuous mode $(15 \mathrm{mg} / \mathrm{ml}$ vancomycin solution, $13 \mathrm{~min}$ ), at different ethylene flow rate: (a) $5 \mathrm{sccm}$, (b) $20 \mathrm{sccm}$, (c) $50 \mathrm{sccm}$, (d) $200 \mathrm{sccm}$. b) adapted from ref. 47 by permission of The Royal Society of Chemistry

On the other hand, Figure 3 clearly shows that, keeping the flow rate of ethylene at $20 \mathrm{sccm}$ and increasing the deposition time in the range 1-13 $\mathrm{min}$, the surface of the coatings gets increasingly crowded of nano-capsules.

A qualitative evaluation of Figures 4a-c shows that, when varying the concentration of vancomycin in the aerosol-forming solution in the range $5-15 \mathrm{mg} / \mathrm{mL}$, the morphology of the coating stays unchanged. However, as shown in Figure 4d, a further lowering of the concentration to $1 \mathrm{mg} / \mathrm{mL}$ impacts, indeed, the morphology of the coating decreasing the density and size of the spheres. Capsules are absent when the same plasma process is carried out with vancomycin-free aerosols (not shown). 


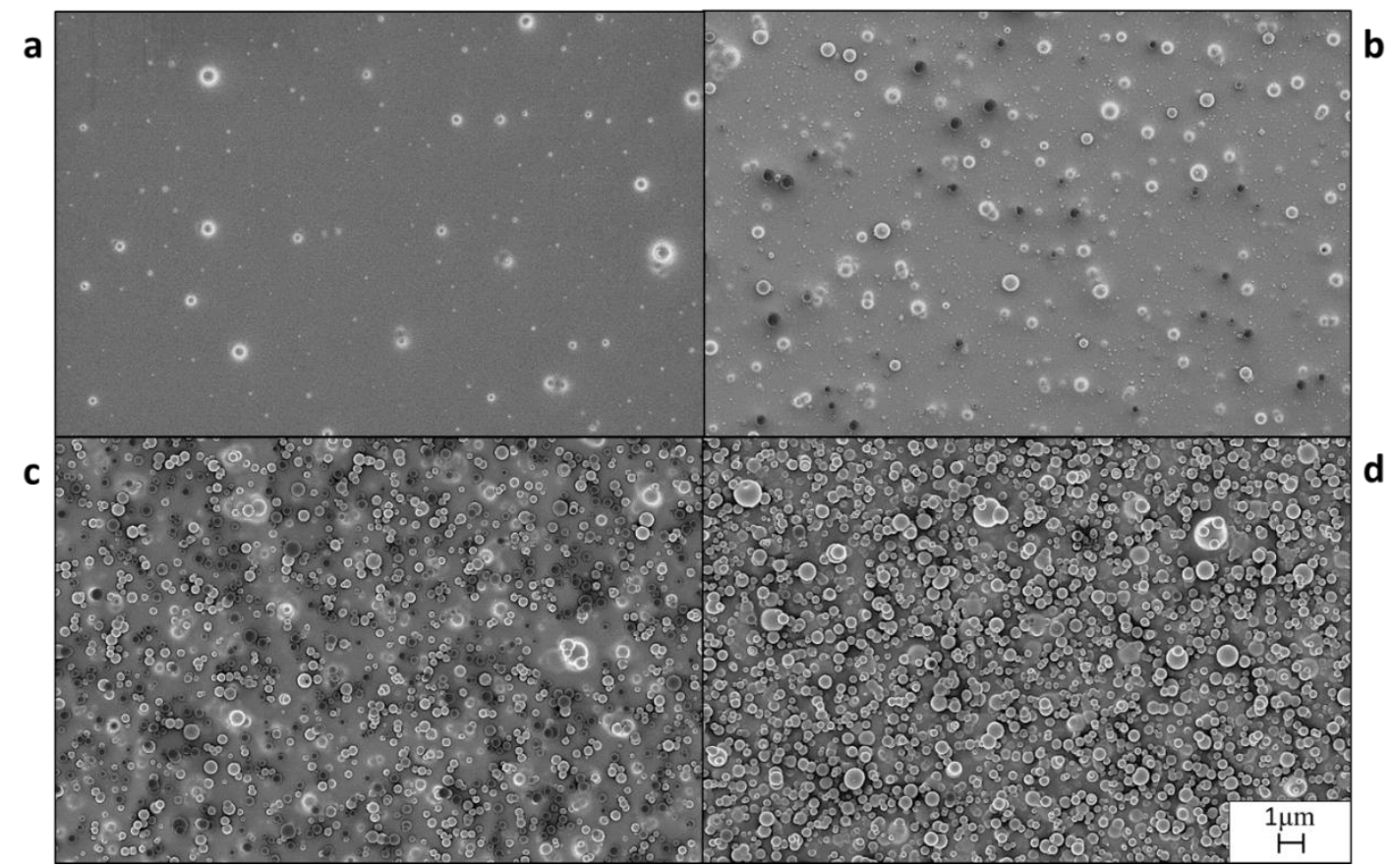

Figure 3 - SEM images of coatings deposited in continuous mode $(15 \mathrm{mg} / \mathrm{ml}$ of vancomycin solution, $20 \mathrm{sccm}$ of ethylene) at different discharge duration: (a) $1 \mathrm{~min}$, (b) $5 \mathrm{~min}$, (c) $10 \mathrm{~min}$, (d) $13 \mathrm{~min}$. d) adapted from ref. 47 by permission of The Royal Society of Chemistry

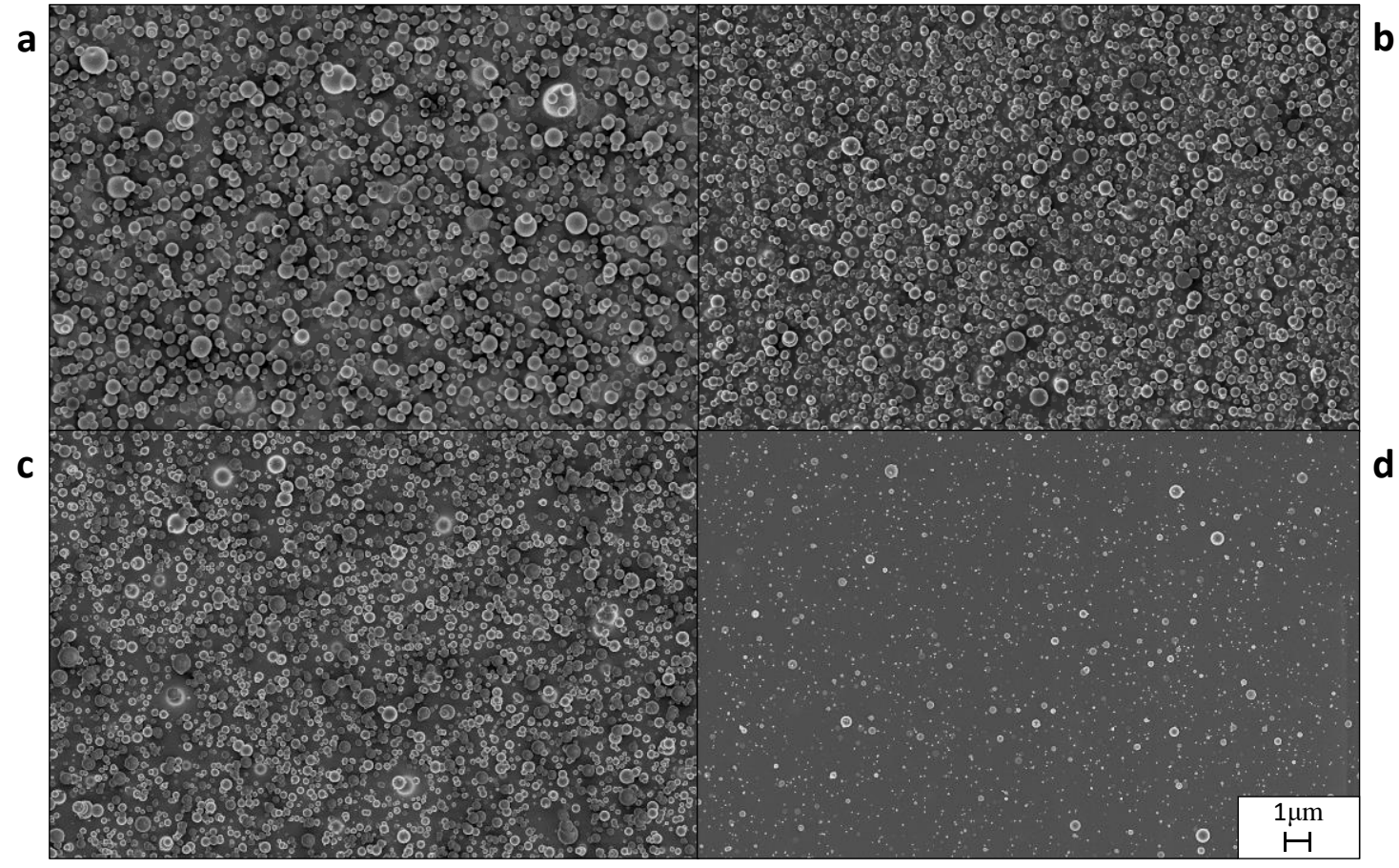

Figure 4 - SEM images of coatings deposited in continuous mode (20 sccm ethylene, 13 min), with an aerosol solution containing (a) 15 , (b) 10 , (c) 5 , (d) $1 \mathrm{mg} / \mathrm{ml}$ of vancomycin. a) adapted from ref. 47 by permission of The Royal Society of Chemistry 
The results shown so far led us to hypothesize the deposition mechanism schematically illustrated in Figure 5 for the nano-capsules formation; the advancement of the deposition process is a function, amongst other parameters, of the distance from the feed inlet and the deposition time. In particular, it is possible to identify three main steps:

I. ethylene molecules enter in the plasma zone with He carrier (not shown in the scheme), along with the aerosol droplets containing water and vancomycin;

II. partial evaporation from the aerosol droplets and fragmentation of water takes place in the plasma zone, along with the fragmentation/activation of the ethylene precursor, giving rise to polymerization both at the surface of the substrate and at the surface of the aerosol droplets; at the same time the droplets, coated and uncoated, adsorb at the surface of the substrate where the polymerization proceeds;

III. The droplets adsorbed at the surface of the substrate become partially covered by and embedded in the growing hydrocarbon-like matrix. At the end of the deposition process, the overall deposited layer results composed by spherical nano-capsules partially embedded in or leant on a flat film; the spheres are composed by a vancomycin-containing core and a hydrocarbon polymer-like shell.

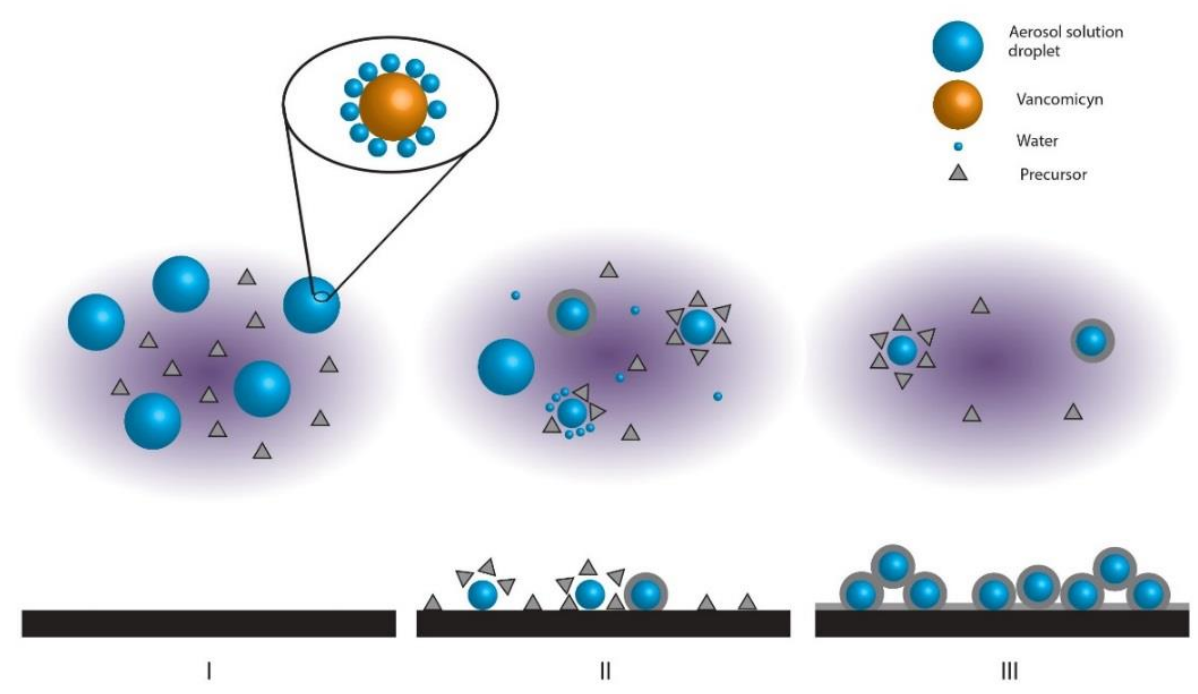


Figure 5 - Scheme of the hypothesized deposition mechanism.

The SEM morphological analyses illustrated in this paper well support the hypothesis formulated on the aerosol-assisted APP deposition mechanisms of the nano-capsule layer. It has to be stressed that the deposition of the nano-capsules occurs, also when other kind of solute is used in the aerosol, in the plasma zone close to the feed inlet, where the feed meets the discharge. More pieces of discussion on the deposition mechanism are delivered below.

If we consider the effect of the ethylene flow rate shown in Figure 2, for example, the low density of spheres obtained at $5 \mathrm{sccm}$ of $\mathrm{C}_{2} \mathrm{H}_{4}$ could be explained by the low amount of polymer precursor fragments available to coat all nanodroplets in the discharge; most of the water evaporates from the nanodroplets, and this results in less spheres at the surface of the substrate. When $200 \mathrm{sccm}$ of $\mathrm{C}_{2} \mathrm{H}_{4}$ are fed, instead, the density of precursor fragments is high enough to initiate a fast polymerization at the surface of the droplets, even the small ones, before they evaporate or aggregate; this results in a higher number of spheres in the deposited layer, with a lower diameter compared to coatings deposited feeding the plasma with 20 and $50 \mathrm{sccm} \mathrm{C}_{2} \mathrm{H}_{4}$.

Regarding the effect of the deposition time shown in Figure 3 we hypothesize that, as the duration time of the discharge proceeds, more spheres are produced in the plasma zone and lean on the substrate, with the small ones that adhered on the bare substrate at the beginning of the deposition process resulting covered and embedded by the growing matrix.

The question could arise about the fate of water, as to whether there is liquid water in the capsules. It is hard to give an exhaustive answer, for the lack of suitable chemical imaging spatially resolved techniques, at the best of the authors' knowledge. However, it is possible to state that though water can be present in the capsules, it should not be in liquid state. In fact, in such a case, once in the 
ultrahigh vacuum of SEM, capsules should burst during the analysis or at least broken capsules residues should be observed. But such phenomena have never been noticed.

The presence of a solute in the aerosol solution appears to be also relevant to the formation of the nano-capsules, as shown in Figure 4. Their number and dimension remain constant first, and then decreases with the concentration of vancomycin in the solution, finally absent when a pure water aerosol is used. This effect could probably be explained with the different stability in the plasma zone of nanodroplets containing different amount of vancomycin chloride.

It should be considered that, as reported in our previous paper, ${ }^{47}$ nano-capsules were also observed when the aerosol solution contained fluorescein, and Chun-Ping Hsiao et al. ${ }^{50}$ reported the presence of similar features when the atomizer was fed with a lysozyme solution. The work carried out up to now, therefore, demonstrates that the presence of a solid solute in the aerosol solution is a key factor in the formation of the spheres. Since the vancomycin concentration used in our experiments is not enough to substantially affect water vapor tension, some effects due to the segregation of the solute at the surface of the nanodroplets could be taken into account. We hypothesize that vancomycin segregates at the surface of the nanodroplets and increases locally the density of the solution; in this way, the droplets surface can better sustain the coating formation. At low or zero concentration, this effect is negligible, thus the coating shell cannot easily form and the water droplet can evaporate or spread over the sample. We can suppose that such molecules can segregate at the drop/gas interface for 2 main reasons:

1) Due to hydrophobic forces leading to orientation of the hydrophobic part of the molecule towards the interface, as characteristic of surfactants

2) Due to electrostatic forces. The drop surface, as in contact with plasma, is likely negatively charged, thus dipoles or ions would orient, at the interface according to the correct polarity. 
Two considerations support the importance of these phenomena. The mentioned molecules are polar or even in ionic form: Fluoresceine and vancomycin are salts, amimo groups of lysozyme in water should be protonized. Furthermore, since it is likely that during the transportation water in the drops would decrease by evaporation, the solute concentration will grow and both phenomena can become more important. Further experiments are necessary for a better comprehension of the role of the solute in stabilizing the droplets.

In order to get some insights into the chemistry of the coating and to verify the presence of vancomycin, FT-IR, WCA and XPS analyses have been carried out. In Figure 6 the normalized absorption FT-IR spectra of films deposited with a CW and a PM plasma are reported, and the FT-IR spectrum of drop-casted vancomycin. Tracks b and c refer to coatings with embedded nano-capsules. A comparison is done with the spectrum of the film obtained by feeding the $\mathrm{CW}$ plasma with ethylene and water aerosol (Figure 6a) and the spectrum of vancomycin solution drop-casted on the substrate (Figure 6d). All deposited coatings exhibit a common hydrocarbon backbone, revealed by the absorption bands relative to $\mathrm{CH}_{2}$ and $\mathrm{CH}_{3}$ stretching $\left(2964-2933 \mathrm{~cm}^{-1}\right), \mathrm{CH}_{2}$ bending $\left(1430-1370 \mathrm{~cm}^{-}\right.$ $\left.{ }^{1}\right)$. Further, the samples, even when vancomycin is absent in the feed, show bands relative to $\mathrm{C}=\mathrm{O}$ $\left(1712-1658 \mathrm{~cm}^{-1}\right)$ and $\mathrm{OH}$ stretching $\left(3371 \mathrm{~cm}^{-1}\right)$, testifying the action of oxidized water fragments (O atoms, $\mathrm{OH}$ radicals) in the deposition mechanism. The spectra of the coatings containing vancomycin exhibit the characteristic absorption bands of vancomycin: in particular, the bands at $3300 \mathrm{~cm}^{-1}$ and $1502 \mathrm{~cm}^{-1}$, due to $\mathrm{NH}_{\mathrm{x}}$ group and the one at $1232 \mathrm{~cm}^{-1}$. Such bands, though not specific, are likely related to the presence of vancomycin. Since these absorption bands are more intense in the spectra of the coating plasma deposited in PM conditions, it can be inferred that in this case films with a higher vancomycin (or vancomycin-like)/hydrocarbon relative content have been obtained. 


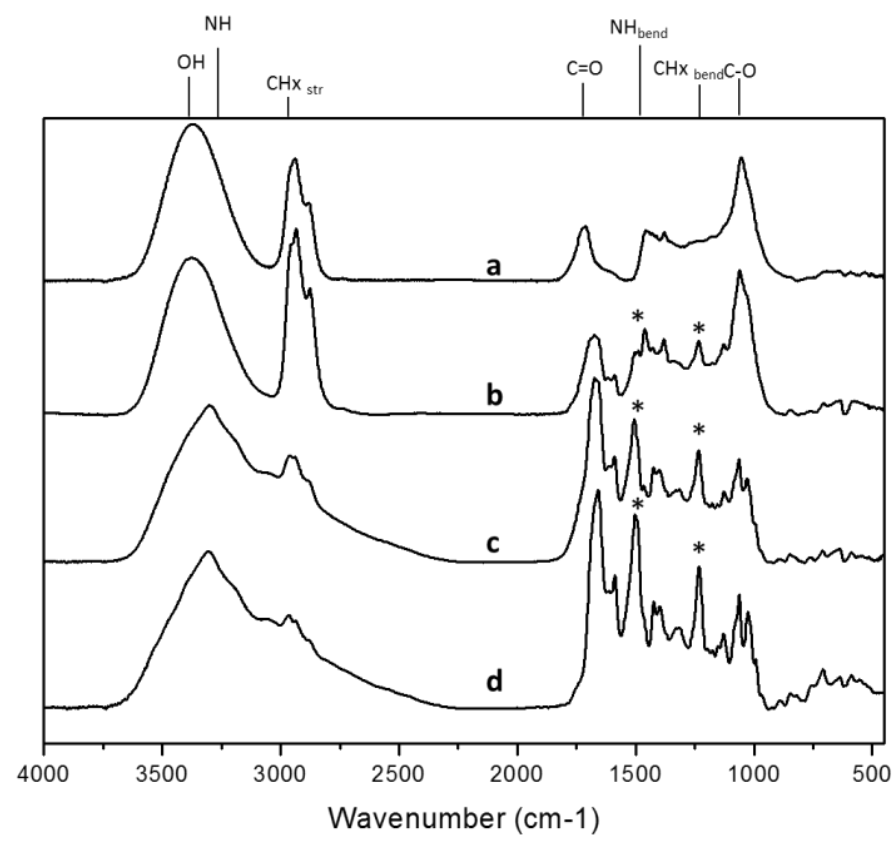

Figure 6 - FT-IR transmission spectra of coating deposited (20 sccm of $\left.\mathrm{C}_{2} \mathrm{H}_{4}\right)$ in different conditions on Silicon substrates: a) feeding the $\mathrm{CW}$ plasma with $\mathrm{C}_{2} \mathrm{H}_{4}$ and water aerosol, b) feeding the $\mathrm{CW}$ plasma with $\mathrm{C}_{2} \mathrm{H}_{4}$ and vancomycin containing aerosol $(15 \mathrm{mg} / \mathrm{ml})$, c) feeding the PM (DC 33\%) plasma with $\mathrm{C}_{2} \mathrm{H}_{4}$ and vancomycin containing aerosol $\left.(15 \mathrm{mg} / \mathrm{ml}), \mathrm{d}\right)$ drop casted vancomycin.

This could be expected since in a pulsed process, part of the time the plasma is off and as a matter of fact, the deposition of the matrix is drastically reduced. Off time likely does not affect vancomycin deposition, which is mostly transferred to the sample by condensation, hence, the drug deposition rate can be considered independent from the pulse or continuous condition. As a result, the coating is enriched in vancomycin passing from continuous to pulse mode.

The higher vancomycin/hydrocarbon IR absorption bands ratio in the PM coating is confirmed by WCA and XPS analyses, whose results are reported in table 1. Both PM and CW deposited coatings show, indeed, a hydrophilic character, however the PM coatings shows much lower static WCA, while the CW coatings, either embedding vancomycin or not, has close water contact angle.

Concerning XPS analysis, the atomic composition does not change very much with the experimental condition investigated, except when comparing CW and PM. Notably, in continuous mode no heteroatoms relative to vancomycin are detected. The reason is clear: 
i) as reported in table $1, \mathrm{~N}$ and $\mathrm{Cl}$ content in vancomycin is low and, considering that in the coatings the drug is diluted in the matrix, the heteroatoms atomic concentration will be much lower and below the detection limit for XPS.

ii) the escape depth for XPS is much lower than $10 \mathrm{~nm}$, and if vancomycin is mostly in the core of the capsules, it cannot be revealed.

The latter point is important and useful for the discussion on nano-capsules structure since it can further prove the core-shell structure of the features found.

On the other hand, in PM some chlorine and nitrogen can be revealed. This can be ascribed to the likely higher concentration of vancomycin in the coating, and much more to the possibility that in PM some vancomycin just adsorb on the coating during the off time, without being embedded in the capsules. Thus, in this kind of samples, vancomycin is more accessible to XPS.

Table 1. XPS atomic concentration and water contact angle of coatings deposited in CW (with and without vancomycin) and in PM (5 slm of He, $20 \mathrm{sccm}$ of ethylene and $15 \mathrm{mg} / \mathrm{ml}$ of vancomycin in the aerosol). Error onto WCA of $3^{\circ}$.

\begin{tabular}{|c|c|c|c|c|c|}
\hline Sample & $\mathrm{C}_{\mathrm{XPS}}(\%)$ & $\mathrm{O}_{\mathrm{XPS}}(\%)$ & $\mathrm{N}_{\mathrm{XPS}}(\%)$ & $\mathrm{Cl}_{\mathrm{XPS}}(\%)$ & $\mathrm{WCA}\left({ }^{\circ}\right)$ \\
\hline $\begin{array}{c}\text { theoretical } \\
\text { vancomycin }\end{array}$ & 65 & 24 & 9 & 2 & $/ /$ \\
\hline $\begin{array}{c}\text { CW with } \\
\text { vancomycin }\end{array}$ & $76.0 \pm 4.0$ & $24.0 \pm 2.0$ & $/ /$ & $/ /$ & 69 \\
\hline $\begin{array}{c}\text { PM with } \\
\text { vancomycin }\end{array}$ & $70.0 \pm 3.0$ & $26.0 \pm 3.0$ & $3.7 \pm 0.3 .0$ & $0.3 \pm 0.1$ & 20 \\
\hline
\end{tabular}

Since the main application of the coating is as a drug delivery system, the kinetics of the vancomycin release from the coating was monitored. Water has been used as medium for the release test since the coating is supposed to be, in its end use, in contact with aqueous environment. 


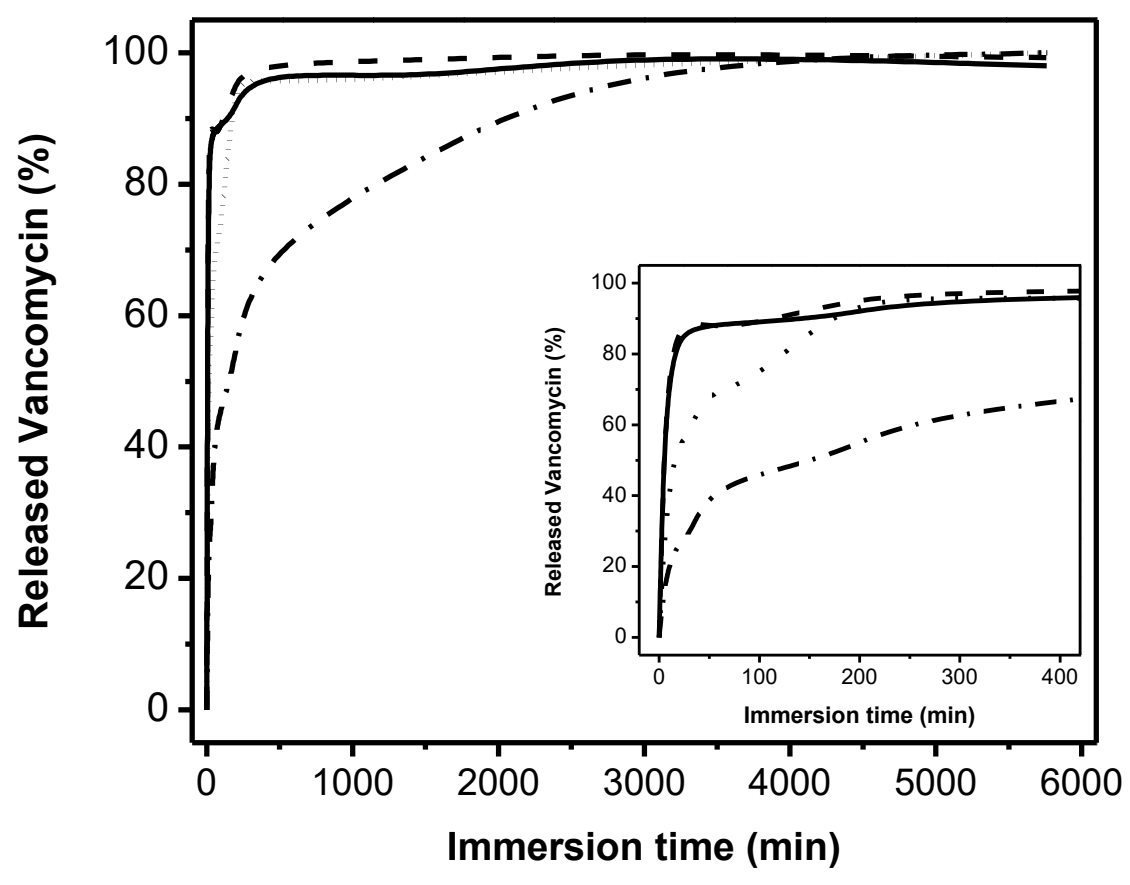

Figure 7 - Percentage of released vancomycin from $1 \mu \mathrm{m}$ thick coatings deposited $(5 \mathrm{slm}$ of $\mathrm{He}, 20$ sccm of ethylene, $15 \mathrm{mg} / \mathrm{ml}$ of vancomycin in the aerosol) in PM without (dash) and with addition of top coating (solid), in CW without (dot), and with the addition of top coating (dash-dot).

The release assay was conducted on $1 \mu \mathrm{m}$ thick composite coatings deposited in CW and in PM conditions, both with and without the addition of a top coating. In Figure 7 it can be appreciated that coatings deposited in pulse mode release vancomycin faster, and the addition of a protective layer has no effect on the kinetics. On the other hand, the drug release from the CW film is slower and, in particular, the percentage of released vancomycin is $75 \%$ after $100 \mathrm{~min}$, less than $50 \%$ with a top coating, while in the same time for the PM case the release is around $90 \%$. Much more, it can be observed that the continuous mode coating takes more than 2 days to release all the leachable drug when the top layer is present. These results can depend on the morphology of the PM film, richer in asperities, offering a higher surface area to contact with water, which makes the release easier and reduces the ability of the top coating to conformably cover the sample surface. 
Finally, from the release test it has been evaluated that in the case of the PM coating the amount of total vancomycin released is about $94 \mu \mathrm{g} / \mathrm{cm}^{2}$, higher than the estimated amount for the CW deposition, $23 \mu \mathrm{g} / \mathrm{cm}^{2}$. Such difference confirms what has been found with IR investigation, due to aerosol solution condensation during the plasma off time in pulse mode.

Going back to the SEM pictures reported in Fig 1c, it can be observed that though most of vancomycin is released in $1 \mathrm{~h}$, most of theof the capsules remains whole. This could indicate that capsule collapsing or cracking do not happen for all the structures upon water immersion, as most of them can stand the loss of the drug.

To further prove the presence of vancomycin in the release extract, a coating has been deposited for $23 \mathrm{~min}$ in PM. Then the sample has been immersed for $30 \mathrm{~min}$ in distilled water and an aliquot of the supernatant analysed with HPLC-MS. An elution peak at the same time as standard vancomycin has been found for the release sample with the mass of 1443,43 amu.

\subsection{Antibacterial activity assay}

The antibacterial activity was evaluated by the agar diffusion and growth test for coatings deposited onto Ti discs with a thickness of $1 \mu \mathrm{m}$ and a $100 \mathrm{~nm}$ barrier coating on top. In the agar diffusion test, it can be observed that the inhibition halo is not evident when the coating is just the matrix, without the drug (Figure 8a); on the other hand, samples coated with vancomycin-containing films give origin to an inhibition zone whose diameter is respectively $3.2 \pm 0.1 \mathrm{~cm}$ for the $\mathrm{CW}$ coating (Figure $8 \mathrm{~b}$ ) and $3.8 \pm 0.5 \mathrm{~cm}$ for the PM coating (Figure $8 \mathrm{c}$ ). 


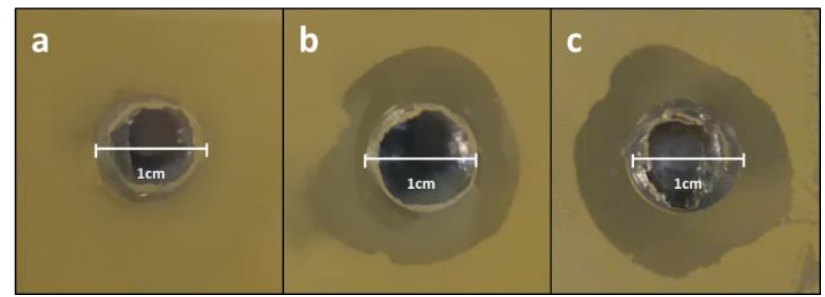

Figure 8 - Inhibition halos in agar from Ti disks coated a) in CW using a vancomycin-free water aerosol, b) in $\mathrm{CW}$ and c) in PM with a vancomycin containing aerosol. $1 \mu \mathrm{m}$ thick coatings deposited with $5 \mathrm{slm}$ of $\mathrm{He} 20 \mathrm{sccm}$ of ethylene and $15 \mathrm{mg} / \mathrm{ml}$ of vancomycin in the aerosol. The composite coatings had a $100 \mathrm{~nm}$ barrier coating on top as described for fig.7.

The bacteria growth rate test results are reported in Figure 9: higher absorbance values of the solutions correspond to highest bacterial concentration. It can be observed that the vancomycin-free coating (a) does not inhibit the bacterial growth, as well as the bare Titanium disk (b). Both coatings containing vancomycin (c and d) completely inhibit the growth of bacterial cells. Hence, both bacterial test considered confirm the antimicrobial activity of the coatings prepared, through release of the drug.

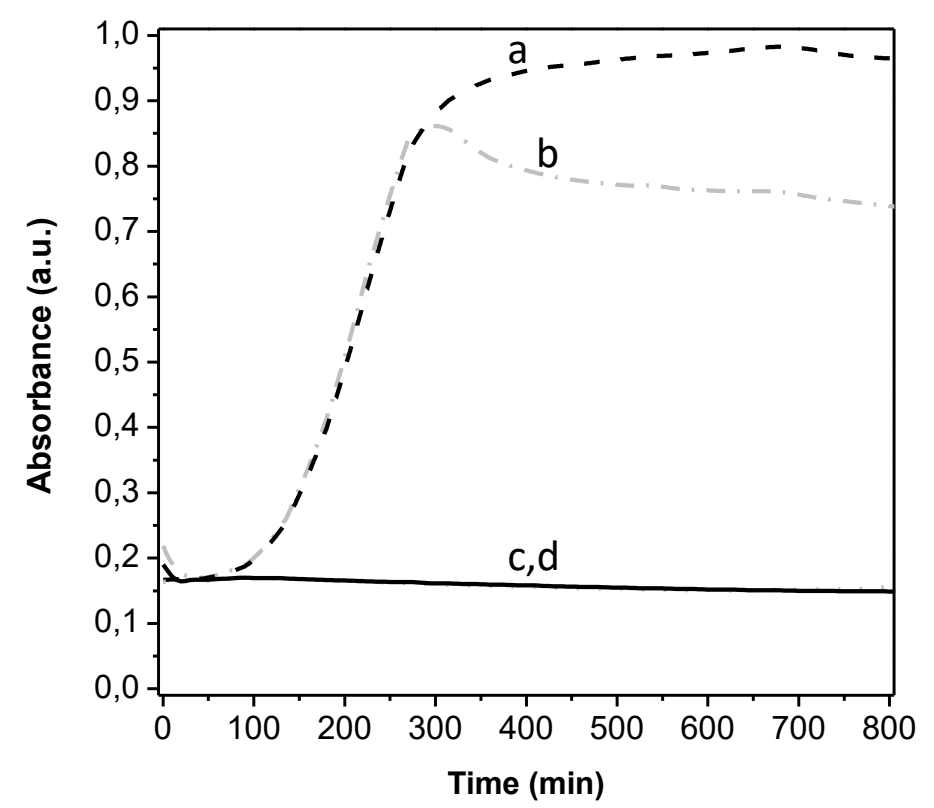

Figure 9 - Growth curves from a) a coating deposited in CW with a vancomycin-free water aerosol, b) Titanium disks, c) a coating deposited in $\mathrm{CW}$ with a vancomycin-containing aerosol, d) a coating deposited in PM with a vancomycin-containing aerosol. The plasma deposited coatings have been 
deposited with a thickness of $1 \mu \mathrm{m}$ with $5 \mathrm{slm}$ of $\mathrm{He}, 20 \mathrm{sccm}$ of ethylene and $15 \mathrm{mg} / \mathrm{ml}$ of vancomycin in the aerosol. The composite coatings had a $100 \mathrm{~nm}$ barrier coating on top as described for fig.7.

\section{Conclusions}

The plasma deposition of vancomycin-containing capsules has been investigated and optimized in this work. The morphological SEM analysis seems to indicate that this deposition process mainly depends onto the flow rate of the matrix precursor, $\mathrm{C}_{2} \mathrm{H}_{4}$, and the concentration of drug in the aerosol solution. In particular, a solid solute in this solution is necessary, otherwise no capsules appear. It is likely that plasma polymerization of the matrix starts around the aerosol droplets, trapping the vancomycin inside the capsule. FTIR and liquid chromatography confirm the presence of vancomycin in the composite coatings.

The kinetics release study has proven that the addition of a barrier top layer can slow down the drug release rate, only in the case of coatings deposited in continuous mode, likely because of the most complex morphology of PM films. A release, lasting two days, has been obtained with a $100 \mathrm{~nm}$ thick top coating.

Bacteria agar diffusion and growth test confirmed the antibacterial activity of the deposited materials, opening up a route to the preparation of drug delivering systems loaded with vancomycin. Despite the complexity of the mechanism hypothesized, this work allowed for a better comprehension of this unique deposition process forming nano-capsules containing drug, by means of atmospheric pressure plasma.

\section{Acknowledgment}


The authors would like to acknowledge Dr Giuseppe Mascolo for HPLC measurement, Savino Cosmai and Danilo Benedetti for the skill technical assistance.

The activity reported in this paper has been partly funded Regione Puglia "Apulian Industrial Plasma Laboratory, LIPP" and the Italian Ministry for Education (MIUR) under grant PONa3_00369 SISTEMA. 


\section{References}

[1] P. Nasimi, M. Haidari, International Journal of green nanotechnology, 2013, 1, 1-5.

[2] V. Sinha, A. Singla, S. Wadhawan, R. Kaushik, R. Kumria, K. Bansal, S. Dhawan, International Journal of Pharmaceutics, 2004, 274, 1-33.

[3] Y. Chen, H. Chen, D. Zeng, Y. Tian, F. Chen, J. Feng, J. Shi, ACSnano, 2010, 4, 10, 60016013.

[4] C. Mora-Huertas, H. Fessi, A. Elaissari, International Journal of Pharmaceutics, 2010, 385, $113-142$.

[5] L. Quintieri, B. R. Pistillo, L. Caputo, P. Favia, F. Baruzzi, Innov. Food Sci. Emerg. Technol. 2013, 20, 215.

[6] P. Appendini, J. Hotchkiss, Inno_ati_e Food Science \& Emerging Technologies, 2002, 3, 113126.

[7] H. Miyachi, K. Ikebukuro, K. Yano, H. Aburatani, I. Karube, Biosens. Bioelectron. 2004, 20, 184.

[8] H. Muguruma, A. Hiratsuka, I. Karube, Anal. Chem. 2000, 72, 2671.

[9] K. Yoshimura, K. Hozumi, Microchem. J. 1996, 53, 207.

[10] K. Kojima, A. Hiratsuka, H. Suzuki, K. Yano, K. Ikebukuro, I. Karube, Anal. Chem. 2003, 75, 1116.

[11] M. Magliulo, A. Mallardi, M. Y. Mulla, S. Cotrone, B. R. Pistillo, P. Favia, I. VikholmLundin, G. Palazzo, L. Torsi, Adv. Mater. 2013, 25, 2090.

[12] P. Lisboa, M.-B. Villiers, C. Brakha, P. N. Marche, A. Valsesia, P. Colpo, F. Rossi, Micro Nanosyst. 2011, 3, 83.

[12] F. Patolsky, G. Zheng, O. Hayden, M. Lakadamyali, X. Zhuang, C. M. Lieber, Proc. Natl. Acad. Sci. U. S. A. 2004, 101, 14017.

[14] C. Mao, A. Liu, B. Cao, Angew. Chem. Int. Ed. 2009, 48, 6790.

[15] E. Uttenthaler, M. Schreaml, J. Mandel, S. Drost, Biosens. Bioelectron. 2001, 16, 735. 
[16] L. De Bartolo, S. Morelli, A. Piscioneri, L. C. Lopez, P. Favia, R. d' Agostino, E. Drioli, Biomol. Eng. 2007, 24, 23.

[17] Z. Wang, M. Etienne, F. Guilès, G. Kohring, A. Walcarius, Biosensors and Bioelectronics, 2012, 32, 111-117.

[18] D. Fiedler, A. Thron, U. Soltmann, H. Bottcher, Chem. Mater. 2004, 16, 3040-3044.

[19] M. Kim, W.-K. Jung, G. Kim, Bioprocess Biosyst. Eng. 2013, 36, 1725.

[20] J. Ryu, S. H. Ku, H. Lee, C. B. Park, Adv. Funct. Mater. 2010, 20, 2132.

[21] J. Sun, E. S. Thian, J. Y. H. Fuh, L. Chang, G. S. Hong, W. Wang, B. Y. Tay, Y. S. Wong, Microsyst. Technol. 2012, 18, 2041.

[22] M.-J. Kim, B. Lee, K. Yang, J. Park, S. Jeon, S. H. Um, D.-I. Kim, S. G. Im, S.-W. Cho, Biomaterials 2013, 34, 7236.

[23] L. C. Lopez, R. Gristina, G. Ceccone, F. Rossi, P. Favia, R. d' Agostino, Surf. Coat. Technol. 2005, 200, 1000 .

[24] K. Yoshimura, A. Sakai, T. Horita, K. Hozumi, Polym. J. 1996, 28, 284.

[25] O. Etienne, C. Picart, C. Taddei, Y. Haikel, J. L. Dimarcq, P. Schaaf, J. C. Voegel, J. A. Ogier, C. Egles, Antimicrob. Agents Chemother. 2004, 48, 3662.

[26] A. Guyomard, E. T. Jouenne, J. J. Malandain, G. Muller, K. Glinel, Adv. Funct. Mater. 2008, 18,758 .

[27] H. He, X. Cao, L. J. Lee, J. Control. Release 2004, 95, 391.

[28] Z. Zhang, F. He, R. Zhuo, J. Mol. Catal. B Enzym. 2013, 94, 129.

[29] J. Ji, H. Zhu, J. Shen, Biomaterials 2004, 25, 1859.

[30] I Adamovich, S D Baalrud, A Bogaerts, P J Bruggeman, M Cappelli, V Colombo, U Czarnetzki, U Ebert, J G Eden, P Favia, D B Graves, S Hamaguchi, G Hieftje, M Hori, I D Kaganovich, U Kortshagen, M J Kushner, N J Mason, S Mazouffre, S Mededovic Thagard, H-R Metelmann, A Mizuno, E Moreau, A B Murphy, B A Niemira, G S Oehrlein, Z Lj Petrovic, L C 
Pitchford, Y-K Pu, S Rauf, O Sakai, S Samukawa, S Starikovskaia, J Tennyson, K Terashima, M Turner, M C M van de Sanden, A Vardelle, J. Phys. D: Appl. Phys. 2017, 50, 323001.

[31] Advanced Plasma Technology; d'Agostino R., Favia P., Kawai Y., Ikegami H., Sato N., Arefi-Khonsari F., Eds.; John Wiley \& Sons: Weinhein, Germany, 2008..

[32] F. Palumbo, G. Camporeale, Y. Yang, J.Wu, E. Sardella, G. Dilecce, C. D. Calvano, L. Quintieri, L. Caputo, F. Baruzzi, P. Favia, Plasma Process. Polym. 2015, , 1302-1310.

[33] P. Heyse, M. B. J. Roeffaers, S. Paulussen, J. Hofkens, P. A. Jacobs, B. F. Sels, Plasma Process. Polym. 2008, 5, 186.

[34] P. Heyse, A. Van Hoeck, M. B. J. Roeffaers, J.-P. Raffin, A. Steinbuchel, T. Stoveken, J. Lammertyn, P. Verboven, P. A. Jacobs, J. Hofkens, S. Paulussen, B. F. Sels, Plasma Process. Polym. 2011, 8, 965.

[35] G. Da Ponte, E. Sardella, F. Fanelli, S. Paulussen, P. Favia, Plasma Process. Polym. 2014, 11,345 .

[36] L.-A. O’Hare, L. O’Neill, A. J. Goodwin, Surf. Interface Anal. 2006, 38, 1519.

[37] J. Bardon, J. Bour, D. Del Frari, C. Arnoult, D. Ruch, Plasma Process. Polym. 2009, 6, S655. [38] F. Fanelli, A. M. Mastrangelo, F. Fracassi, Langmuir 2014, 30, 857.

[39] A. Liguori, E. Traldi, E. Toccaceli, R. Laurita, A. Pollicino, M.L. Focarete, V. Colombo, M. Gherardi, Plasma Process. Polym. 2016, 13, 623-632

[40] J. Friedrich, R. Mix, R, Schulze, A. Rau, Journal of Adeshion Science and Technology, 2010, 24, 1329-1350.

[41] A.-M. Le Ray, S. Chiffoleau, P. Iooss, G. Grimandi, A. Gouyette, G. Daculsi, C. Merle, Biomaterials, 2003, 24, 443-449.

[42] E.Cevher, Z. Orhan, L. Mülazımoğlu, D. Şensoy, M. Alper, A. Yı1dız, Y. Özsoy, International Journal of Pharmaceutics, 2006, 317, 127-135.

[43] J. Xu, B. Xu, D. Shou, X. Xia, Y. Hu, Polymers, 2015, 7, 1850-1870. 
[44] F. Ordikhani a, E. Tamjidb, A. Simchi, Materials Science and Engineering C, 2014, 41, 240248.

[45] F. Ordikhani, A. Simchi, Applied Surface Science, 2014, 317, 56-66.

[46] J. Sun, J. Li, H. Fan, S. Ai, J. Mater. Chem. B, 2013, 1, 5436.

[47] C. Lo Porto, F. Palumbo, G. Palazzo, P. Favia, Polym. Chem., 2017, 8, 1746-1749.

[48] Y.-W. Yang, G. Camporeale, E. Sardella, G. Dilecce, J.-S. Wu, F. Palumbo, P. Favia, Plasma Process. Polym. 2014, 11, 1102-1111.

[49] C. Lavay, J. Buxadera-Palomero, M.Avilés, C. Canal, M.P. Ginebra, J. Phys D: Appl Phys, 2016, 49, 304004.

[50] C.-P. Hsiao, C.-C. Wu, Y.-H. Liu, Y.-W. Yang, Y.-C. Cheng, F. Palumbo, G.Camporeale, P. Favia, J.-S. Wu, IEEE Transactions On Plasma Science, 2016, 44, 12, 3091-3098. 


\section{Table of Content}

Drug can be encapsulated in plasma polymerized nano-vescicles by means of aerosol-assisted atmospheric pressure plasma in a dielectric barrier discharge configuration. This is hereby proved for vancomycin containing composite coatings, evidencing the morphology of nanocapsule with a coreshell structure. The growth mechanism proposed is based on the hypothesis that the capsules shell is plasma polymerized around the aerosol nano-droplets before sticking on the substrate. Once deposited such nano-capsules formed film is able to release the drug in water, and much more the antibacterial activity is maintained, as demonstrated against Staphylococcus aureus.

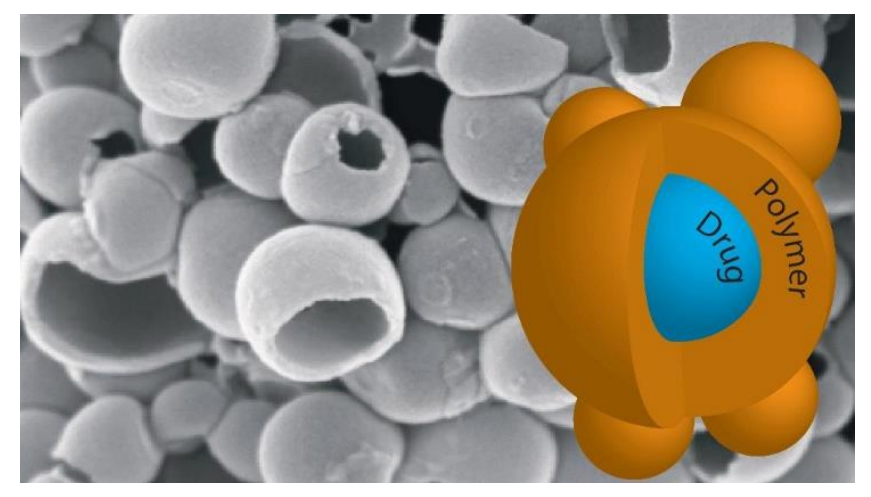

